\title{
RESEARCH
}

Open Access

\section{Extracellular vesicles derived from mesenchymal stromal cells mediate endogenous cell growth and migration via the CXCL5 and CXCL6/CXCR2 axes and repair menisci}

Kazumasa Kawata' ${ }^{1}$, Hideyuki Koga', Kunikazu Tsuji ${ }^{1}$, Kazumasa Miyatake', Yusuke Nakagawa', Takanori Yokota², Ichiro Sekiya ${ }^{3}$ and Hiroki Katagiri ${ }^{1,4^{*}}$

\begin{abstract}
Background: Mesenchymal stromal cell-derived extracellular vesicles (MSC-EVs) are promising candidates for tissue regeneration therapy. However, the therapeutic efficacy of MSC-EVs for meniscus regeneration is uncertain, and the mechanisms underlying MSC-EV-mediated tissue regeneration have not been fully elucidated. The aims of this study were to evaluate the therapeutic efficacy of intra-articular MSC-EV injection in a meniscus defect model and elucidate the mechanism underlying MSC-EV-mediated tissue regeneration via combined bioinformatic analyses.

Methods: MSC-EVs were isolated from human synovial MSC culture supernatants via ultrafiltration. To evaluate the meniscus regeneration ability, MSC-EVs were injected intra-articularly in the mouse meniscus defect model immediately after meniscus resection and weekly thereafter. After 1 and 3 weeks, their knees were excised for histological and immunohistochemical evaluations. To investigate the mechanisms through which MSC-EVs accelerate meniscus regeneration, cell growth, migration, and chondrogenesis assays were performed using treated and untreated chondrocytes and synovial MSCs with or without MSC-EVs. RNA sequencing assessed the gene expression profile of chondrocytes stimulated by MSC-EVs. Antagonists of the human chemokine CXCR2 receptor (SB265610) were used to determine the role of CXCR2 on chondrocyte cell growth and migration induced by MSCEVs.
\end{abstract}

\footnotetext{
* Correspondence: katagiri.orj@tmd.ac.jp

${ }^{1}$ Department of Joint Surgery and Sports Medicine, Graduate School of

Medical and Dental Sciences, Tokyo Medical and Dental University (TMDU),

1-5-45 Yushima, Bunkyo-ku, Tokyo 113-8519, Japan

${ }^{4}$ Department of Orthopedics, Dokkyo Medical University Saitama Medical

Center, 2-1-50 Minamikoshigaya, Koshigaya, Saitama 343-8555, Japan

Full list of author information is available at the end of the article
}

(c) The Author(s). 2021 Open Access This article is licensed under a Creative Commons Attribution 4.0 International License, which permits use, sharing, adaptation, distribution and reproduction in any medium or format, as long as you give appropriate credit to the original author(s) and the source, provide a link to the Creative Commons licence, and indicate if changes were made. The images or other third party material in this article are included in the article's Creative Commons licence, unless indicated otherwise in a credit line to the material. If material is not included in the article's Creative Commons licence and your intended use is not permitted by statutory regulation or exceeds the permitted use, you will need to obtain permission directly from the copyright holder. To view a copy of this licence, visit http://creativecommons.org/licenses/by/4.0/. The Creative Commons Public Domain Dedication waiver (http://creativecommons.org/publicdomain/zero/1.0/) applies to the data made available in this article, unless otherwise stated in a credit line to the data. 
Results: In the meniscus defect model, MSC-EV injection accelerated meniscus regeneration and normalized the morphology and composition of the repaired tissue. MSC-EVs stimulated chondrocyte and synovial MSC cell growth and migration. RNA sequencing revealed that MSC-EVs induced 168 differentially expressed genes in the chondrocytes and significantly upregulated CXCL5 and CXCL6 in chondrocytes and synovial MSCs. Suppression of CXCL5 and CXCL6 and antagonism of the CXCR2 receptor binding CXCL5 and CXCL6 negated the influence of MSC-EVs on chondrocyte cell growth and migration.

Conclusions: Intra-articular MSC-EV administration repaired meniscus defects and augmented chondrocyte and synovial MSC cell growth and migration. Comprehensive transcriptome/RNA sequencing data confirmed that MSCEVs upregulated CXCL5 and CXCL6 in chondrocytes and mediated the cell growth and migration of these cells via the CXCR2 axis.

Keywords: Extracellular vesicles, Meniscus regeneration, Mesenchymal stromal cell, RNA sequencing, CXCR2

\section{Background}

Meniscus tears and defects alter the biomechanical function and accelerate the progression of osteoarthritis (OA) [1-4]. The intact meniscus plays an important role in load bearing. Hence, meniscus tears and defects decrease transmission function and increase tibiofemoral contact pressure by $\leq 2$-fold $[1,5$, 6]. Moreover, meniscus tears and defects increase the risk of OA by $2-8$-fold compared to that in the general population without meniscus tears $[7,8]$. Knee replacement using an artificial joint is a treatment option for patients with end-stage knee $\mathrm{OA}$, and more than 790,000 knee replacements are performed each year in the USA. Consequently, the orthopedic community has emphasized the importance of "saving the meniscus" $[9,10]$. However, this tissue has limited intrinsic capacity for regeneration because of the low cellularity of endogenous recruited cells. Additionally, no disease-modifying treatment can regenerate meniscus defects and tears, highlighting the need for novel technologies.

Mesenchymal stromal cells (MSCs) have been shown to be promising candidates for meniscus regeneration therapy in an animal model $[11,12]$. The regeneration capacity of MSCs has been attributed to secreted trophic factors, such as extracellular vesicles (EVs) [13]. EVs are nano-sized membrane vesicles comprising bioactive lipids, nucleic acids (mRNAs and microRNAs), and proteins, which play vital roles in cell-cell communication [14]. EVs lack immunogenicity; thus, they demonstrate potential as a cell-free drug for tissue regeneration in an animal model [15]. Furthermore, they have displayed therapeutic efficacy against ischemic heart disease [16] and kidney disease [17] and promoted wound healing [18] and cartilage regeneration [19]. However, the therapeutic efficacy of EVs in meniscus regeneration is uncertain.

Studies have investigated the mechanism of EV-induced tissue regeneration. Possible modes of action include enhanced cell viability and growth [20], reduced apoptosis [21], and modulation of inflammatory responses [22]. However, these mechanisms of action have not been fully elucidated [23] and therefore need to be clarified in order to optimize the clinical use of EVs.

Here, we evaluated the therapeutic efficacy of an intraarticular MSC-EV injection in a mouse model of meniscus defect. We analyzed the mechanism of EV-mediated tissue regeneration using combined bioinformatics analyses. The mouse meniscus defect model has been used to generate proof-of-concept data for meniscus regeneration [11]. Chondrocytes are the main components of the meniscus [24], and endogenous synovial MSCs infiltrate regenerated meniscus tissue [25]. Therefore, we performed in vivo and in vitro experiments using chondrocytes and synovial MSCs. In addition, combined bioinformatics analyses were performed based on the gene expression data from chondrocytes and synovial MSCs.

\section{Methods}

\section{Preparation of synovial MSCs and chondrocytes}

All human procedures were approved by the Local Ethical Committee for Human Research (Tokyo Medical and Dental University, Tokyo, Japan; Approval No.2121). Synovial MSCs were isolated and cultured from the synovium, as previously described [26]. Briefly, the synovia were harvested from patients who provided written, informed consent to participate in this research prior to undergoing anterior cruciate ligament reconstruction. Participants comprised four males and one female. The mean patient age was $22.0 \pm 4.56$ years. Synovial MSCs were isolated from the synovium by immersing in collagenase and dispase for $3 \mathrm{~h}$ followed by filtration through a $70 \mu \mathrm{m}$ mesh (Becton Dickinson, Franklin Lakes, NJ, USA). The digested cells were incubated in a complete culture medium (alpha minimal essential medium [MEM] supplemented with $10 \%[\mathrm{v} / \mathrm{v}]$, fetal bovine serum [FBS], and $1 \%[\mathrm{w} / \mathrm{v}]$ penicillin-streptomycin-amphotericin B [Invitrogen; Thermo Fisher Scientific, Waltham, MA, USA]) under a humidified $5 \% \mathrm{CO}_{2}$ atmosphere at $37^{\circ} \mathrm{C}$. Synovial MSCs were 
used at passages 3-6 in all experiments. Chondrocytes were isolated from cartilage tissues as previously described [27]. Briefly, the cartilage tissue was harvested from patients who had undergone total knee arthroplasty. The cartilage tissues were digested in $3 \mathrm{mg} / \mathrm{mL}$ collagenase for $6 \mathrm{~h}$. The nucleated cells were filtered, plated at $10^{4}$ cells per $60 \mathrm{~cm}^{2}$ dish, and cultured as passage 0 for 14 days. The cells were cultured in Dulbecco's modified Eagle's medium (DMEM)-F12 supplemented with $5 \%(\mathrm{v} / \mathrm{v})$ FBS, $5 \mathrm{mg} / \mathrm{mL}$ ITS + Premix (Becton Dickinson), and 1\% (w/v) penicillin-streptomycinamphotericin B (Invitrogen; Thermo Fisher Scientific) under a humidified $5 \% \mathrm{CO}_{2}$ atmosphere at $3{ }^{\circ} \mathrm{C}$. Chondrocytes were used at passages $3-5$ in all experiments.

\section{Differentiation assay of synovial MSCs}

Calcification induction culture was conducted as previously described [28]. Briefly, 100 cells were cultured for 14 days in a complete culture medium on a $60-\mathrm{cm}^{2}$ dish. Consequently, these adherent cells were cultured in an osteogenic induction medium $(50 \mu \mathrm{g} / \mathrm{mL}$ ascorbic acid 2-phosphate [Sigma-Aldrich, St. Louis, MO, USA], 10 $\mathrm{nM}$ dexamethasone [Sigma-Aldrich], and $10 \mathrm{mM} \beta$ glycerophosphate [Sigma-Aldrich], in a complete culture medium). The osteogenic induction medium was changed every 3-4 days. After 21 days, alizarin red staining (EMD Millipore, Billerica, MA, USA) confirmed the differentiation of these cells into osteoblasts. Adipogenic induction culture was performed as previously described [28]. Adherent cells were cultured in the adipogenic induction medium (100 nM dexamethasone [Sigma-Aldrich], $0.5 \mathrm{mM}$ isobutylmethylxanthine [Sigma-Aldrich], and $100 \mathrm{mM}$ indomethacin [Wako Pure Chemical Industries Ltd., Osaka, Japan] in a complete culture medium). The adipogenic induction medium was changed every 3-4 days. After 21 days, the differentiation of these cells into adipocytes was assessed using oil red-O staining (Muto Pure Chemicals, Tokyo, Japan). Chondrogenic differentiation by pellet culture was conducted as previously described [26]. Briefly, $1.5 \times 10^{6}$ synovial MSCs were cultured in a $15-\mathrm{mL}$ polypropylene tube (Becton Dickinson) and centrifuged at $1500 \mathrm{rpm}$ for $10 \mathrm{~min}$ to form pellets. The pellets were then cultured in a $400-\mu \mathrm{L}$ chondrogenesis medium for 21 days. The pellets were fixed, embedded in paraffin, cut into $5 \mu \mathrm{m}$ sections, and stained with Toluidine Blue for histological evaluation.

\section{Flow cytometric analysis of synovial MSCs}

Cell surface molecules were analyzed using a flow cytometer (FACSVerse TM, BD Biosciences, Tokyo, Japan). Briefly, cultured cells $\left(1-5 \times 10^{5}\right.$ cells $\left./ \mathrm{mL}\right)$ were washed twice with FACS staining buffer and counted. Cells $(100,000)$ were incubated with antibodies targeting the molecules or isotype of interest. Detailed information on each antibody is provided in Supplementary Table 1. Isotypes were used to establish staining specificity. All analyses were performed using BD FACSVerse TM and BD FACSSuite TM Software (BD Biosciences, Tokyo, Japan).

\section{MSC-EV isolation and identification}

Synovial MSCs were seeded at $1.5 \times 10^{6}$ cells per 15 $\mathrm{cm}^{2}$ plate and incubated in a complete culture medium for $24 \mathrm{~h}$. The cells were then washed twice with phosphate-buffered saline (PBS) and cultured with alpha MEM containing 5\% exosome-depleted FBS (SBI, Palo Alto, CA, USA) or serum-free alpha MEM for $48 \mathrm{~h}$. The cell suspension was centrifuged at $2000 \times g$ and $4{ }^{\circ} \mathrm{C}$ for $10 \mathrm{~min}$ to remove detached cells. The supernatant was collected and passed through a $0.22-\mu \mathrm{m}$ filter (EMD Millipore, Billerica, MA, USA) to remove cellular debris. The filtered supernatant was then transferred to the upper compartment of a $10-\mathrm{kDa}$ Amicon Ultra Filter Unit (EMD Millipore, Billerica, MA, USA) and centrifuged at $4000 \times g$ and $4{ }^{\circ} \mathrm{C}$ for $30 \mathrm{~min}$. The liquid was washed with PBS and subjected to ultrafiltration. The MSC-EVs were collected from the upper compartment and stored in a PROKEEP low-protein binding tube (WATSON, Tokyo, Japan) at $-80^{\circ} \mathrm{C}$. Nanoparticle tracking analysis (NTA) was performed on the EVs using NanoSight LM10 and NanoSight NTA v3.0 (Malvern Panalytical, Malvern, UK). Western blotting was used to identify the EV-associated markers CD9 and CD63. MSC-EVs were negatively stained with $2 \%(\mathrm{w} / \mathrm{v})$ uranyl acetate, and their morphology was observed under a transmission electron microscope (TEM; JEM-1400 Flash; JEOL Ltd., Tokyo, Japan).

\section{Cell growth assay}

The cell growth assay was conducted as previously described [29]. Chondrocytes and synovial MSCs were seeded in a 96well plate at a density of $1 \times 10^{5}$ cells/well. The cells were treated with either $2 \times 10^{9}$ particles/mL MSC-EVs or PBS vehicle control. Cell growth was measured on days $0,3,7$, 10, and 13, with a Cell Counting Kit-8 (CCK-8; Dojindo, Kumamoto, Japan) according to the manufacturer's instructions. Ten microliters of CCK- 8 reagent was added to each well, and the plate was incubated at $37^{\circ} \mathrm{C}$ for $1.5 \mathrm{~h}$. Absorbances were measured at $450 \mathrm{~nm}$ in an Infinite ${ }^{\circ} \mathrm{F} 50$ Absorbance Microplate Reader (Tecan Trading A, Männedorf, Switzerland). Chondrocytes and synovial MSCs were cultured in six-well plates using the above methods. The cells were fixed in $4 \%(\mathrm{v} / \mathrm{v})$ paraformaldehyde (PFA) and stained with $0.5 \%(\mathrm{w} / \mathrm{v})$ crystal violet (Wako Pure Chemical Industries Ltd.).

\section{Cell migration assay}

The effects of MSC-EVs on the migration of chondrocytes and synovial MSCs were evaluated by a Transwell ${ }^{\circ}$ migration assay. The upper chamber contained $5 \times 10^{4}$ 
cells per $100 \mu \mathrm{L}$ serum-free medium. Each lower chamber contained $500 \mu \mathrm{L}$ complete culture medium with or without $4 \times 10^{9}$ particles/mL MSC-EVs. Chondrocytes were incubated for $24 \mathrm{~h}$, and synovial MSCs were incubated for $12 \mathrm{~h}$ at $37^{\circ} \mathrm{C}$. After incubation, the upper chamber was fixed with $4 \%(\mathrm{v} / \mathrm{v})$ PFA for $5 \mathrm{~min}$, stained with $0.5 \%(\mathrm{w} / \mathrm{v})$ crystal violet for $10 \mathrm{~min}$, and washed three times with PBS. The upper surface of the Transwell membrane was wiped with a cotton swab to remove the cells. The cells were counted in five randomly selected fields at $\times 100$ (Olympus BX 53; Olympus, Tokyo, Japan).

\section{MSC chondrogenesis assay}

The effects of the MSC-EVs on synovial MSC chondrogenesis were evaluated by pellet culture, as previously described [26]. Briefly, $1.5 \times 10^{6}$ synovial MSCs were cultured in a 15$\mathrm{mL}$ polypropylene tube (Becton Dickinson) and centrifuged at $1500 \mathrm{rpm}$ for $10 \mathrm{~min}$ to form pellets. The pellets were then cultured with either $2 \times 10^{9}$ particles/mL MSC-EVs or PBS in $400 \mu \mathrm{L}$ chondrogenesis medium (high-glucose Dulbecco's modified Eagle's medium (Invitrogen; Thermo Fisher Scientific) supplemented with $1000 \mathrm{ng} / \mathrm{mL}$ BMP-7 (Stryker Biotech, Kalamazoo, MI, USA), $10 \mathrm{ng} / \mathrm{mL}$ TGF- $\beta 3$ (R\&D Systems, Minneapolis, MN, USA), $100 \mathrm{nmol} / \mathrm{L}$ dexamethasone, $50 \mathrm{ng} / \mathrm{mL}$ ascorbate-2-phosphate, $40 \mathrm{mg} / \mathrm{mL}$ proline, $100 \mathrm{~g} / \mathrm{mL}$ pyruvate (Sigma-Aldrich), and $50 \mathrm{mg} / \mathrm{mL}$ ITS + Premix [Becton Dickinson]) for 21 days. The pellets were fixed, embedded in paraffin, cut into 5 - $\mu \mathrm{m}$ sections, and stained with Toluidine Blue for histological evaluation.

\section{Mouse meniscal defect model}

The animal study protocol was approved and conducted in accordance with the guidelines of the Institutional Animal Care and Use Committee of Tokyo Medical and Dental University (Approval No. A2020-132A). Male C57BL/6J mice were purchased from Oriental Yeast Co. Ltd. (Tokyo, Japan), housed in an environmentally controlled animal facility under a 12-h light/12-h dark cycle, and provided with food and water ad libitum. Twentyfour male mice aged 8 weeks were used in the study. Defects were made on the anterior medial menisci, as previously described [30]. Briefly, a straight incision was made on the anterior side of the knee under isoflurane inhalation anesthesia. The joint capsule was cut, and the anterior medial meniscus horn was exposed. The medial meniscus was cut vertically at the medial collateral ligament level and excised under a stereomicroscope (Zeiss Stemi 2000C; Carl Zeiss AG, Oberkochen, Germany). To evaluate MSC-EV regeneration, based on the EV concentration reported previously [29], $10^{8}$ MSC-EV particles per $10 \mu \mathrm{L}$ PBS were injected intra-articularly into the left knee $(n=6)$. Control treatment consisted of $10 \mu \mathrm{L}$ PBS, which was injected into the contralateral right knees $(\mathrm{n}=6)$. Intra-articular injections were performed immediately after meniscus resection and weekly thereafter. After 1 and 3 weeks, the mice were euthanized by $\mathrm{CO}_{2}$ inhalation, and their knees were excised for histological and immunohistochemical evaluations.

\section{Histological evaluation}

Knee samples were fixed in 4\% (v/v) PFA for 7 days, decalcified in $20 \%(\mathrm{w} / \mathrm{v})$ ethylenediaminetetraacetic acid (EDTA) for 10 days, dehydrated, and embedded in paraffin. The samples were cut in the sagittal plane to $5 \mu \mathrm{m}$ thickness and stained with safranin-O/fast green and hematoxylin and eosin (HE) to evaluate meniscus regeneration with a modified Pauli's scoring system (Supplemental Table 2) [30]. Safranin-O-positive areas in the estimated post-regeneration menisci were measured using Image v1.52p (National Institutes of Health, Bethesda, MD, USA). The Pauli scores were evaluated by two independent observers blinded to the treatments.

\section{Immunohistochemical evaluation}

Tissue sections were deparaffinized in xylene (Wako Pure Chemical Industries Ltd.), rehydrated in graded alcohol, and saturated with PBS. For type II collagen staining and antigen retrieval, the samples were pretreated with $0.4 \mathrm{mg} / \mathrm{mL}$ proteinase $\mathrm{K}$ (Agilent Technologies, Santa Clara, CA, USA) in $50 \mathrm{mM}$ Tris- $\mathrm{HCl}$ buffer (Wako Pure Chemical Industries Ltd.) for $5 \mathrm{~min}$ at room temperature. For proliferative cell nuclear antigen (PCNA) staining, the samples were pretreated with Target Retrieval Solution 10X ( $\times 10$ dilution; Agilent Technologies) for $30 \mathrm{~min}$. Endogenous peroxidase was quenched by incubating in $0.3 \%(\mathrm{v} / \mathrm{v})$ hydrogen peroxide in methanol for $30 \mathrm{~min}$. Tissues were blocked with 5\% $(\mathrm{v} / \mathrm{v})$ goat or horse serum plus $1 \%(\mathrm{v} / \mathrm{v})$ BSA in PBS. The slices were incubated with primary antibodies at $4{ }^{\circ} \mathrm{C}$ overnight. The primary antibodies comprised mouse anti-type I collagen (1:200 dilution; ab34712; Abcam, Cambridge, UK), mouse anti-type II collagen (1:1000 dilution; ab34712; Abcam), and anti-PCNA (1:1000 dilution; ab53048; Abcam). The tissue sections were rinsed with $0.1 \%(\mathrm{v} / \mathrm{v})$ PBS-Triton X-100 (MP Biomedicals, Santa Ana, CA, USA) and incubated in 1:200 secondary antibodies. The secondary antibodies included biotinylated goat anti-rabbit IgG for types I and II collagen (Vector Laboratories, Burlingame, CA, USA) and biotinylated horse anti-mouse IgG for anti-PCNA (Vector Laboratories). The tissue sections were rinsed with PBS, and signals were visualized using Vectastain $A B C$ reagent (Vector Laboratories) followed by 3,3'-diaminobenzidine (DAB) staining (Vector Laboratories). The tissue sections were counterstained with hematoxylin (Muto Pure Chemicals). PCNA-positive/negative stained cells in the estimated post-regeneration meniscus were 
enumerated at $\times 400$ magnification (Olympus BX 53). The cells were counted in three separate areas per sample by two independent observers blinded to the treatments.

\section{RNA sequencing}

Chondrocytes and synovial MSCs were seeded in six-well plates at $1.2 \times 10^{5} /$ well, incubated for $48 \mathrm{~h}$, and cultured with $2 \times 10^{9}$ particles/mL MSC-EVs or PBS for $24 \mathrm{~h}$. The cells were subjected to RNA sequencing on a BGISEQ-500 by BGI Co. Ltd. (Beijing, China). Differentially expressed genes (DEGs) were identified as those with Q (adjusted P) $\leq 0.05$ according to a previously described method [31]. DEGs were visualized with a volcano diagram plotted using a $\log 2$ scale and Q. DEGs were analyzed using the Kyoto Encyclopedia of Genes and Genomes (KEGG) pathway database (http://www. genome.jp/kegg/). Data are shown in Supplementary Table 3.
Real-time quantitative polymerase chain reaction (qRTPCR)

Chondrocytes were prepared in the same way as described for RNA sequencing. Total RNA was extracted from cells using a High Pure RNA isolation kit (Roche Diagnostics, Mannheim, Germany), according to the manufacturer's instructions. The cDNA was synthesized with a Transcriptor First Strand cDNA synthesis kit (Roche Diagnostics). RT-qPCR was performed in a LightCycler 480 Probe Master kit (Roche Diagnostics). Relative mRNA quantities were normalized to those of $\beta$-actin, as previously described [32]. The PCR primer sequences are listed in Supplementary Table 4.

\section{Western blotting}

Western blotting was performed as previously described [33]. Briefly, chondrocytes were starved in $0.5 \%(\mathrm{v} / \mathrm{v})$
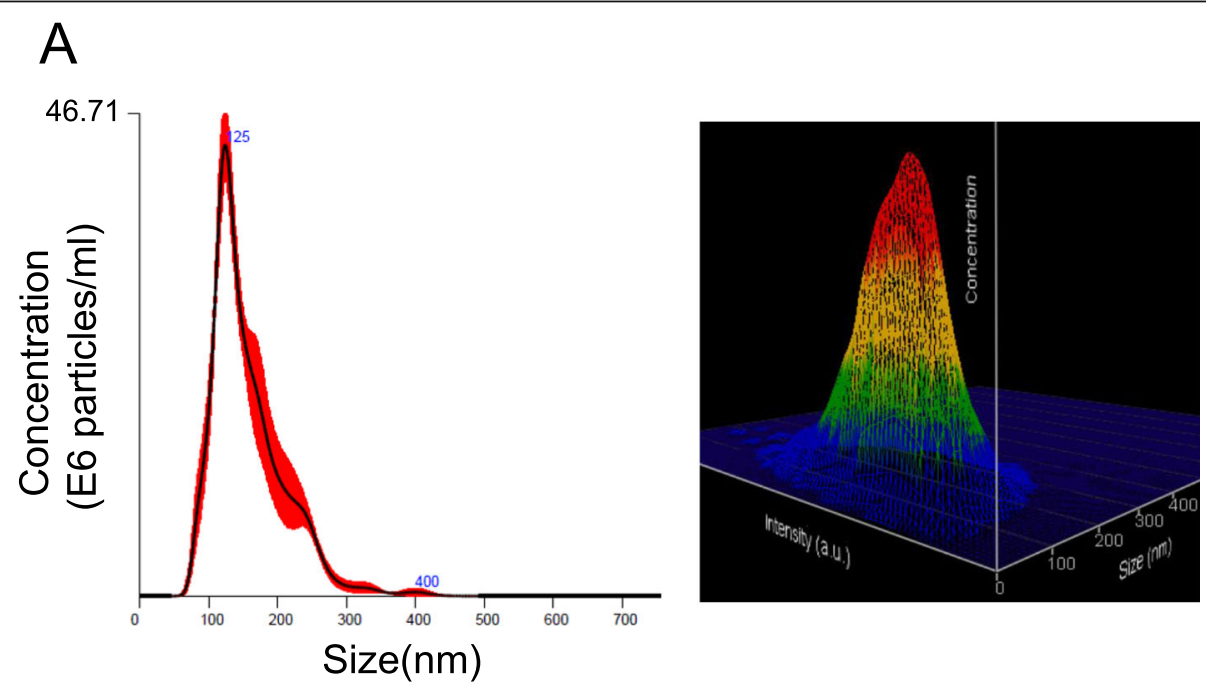

B
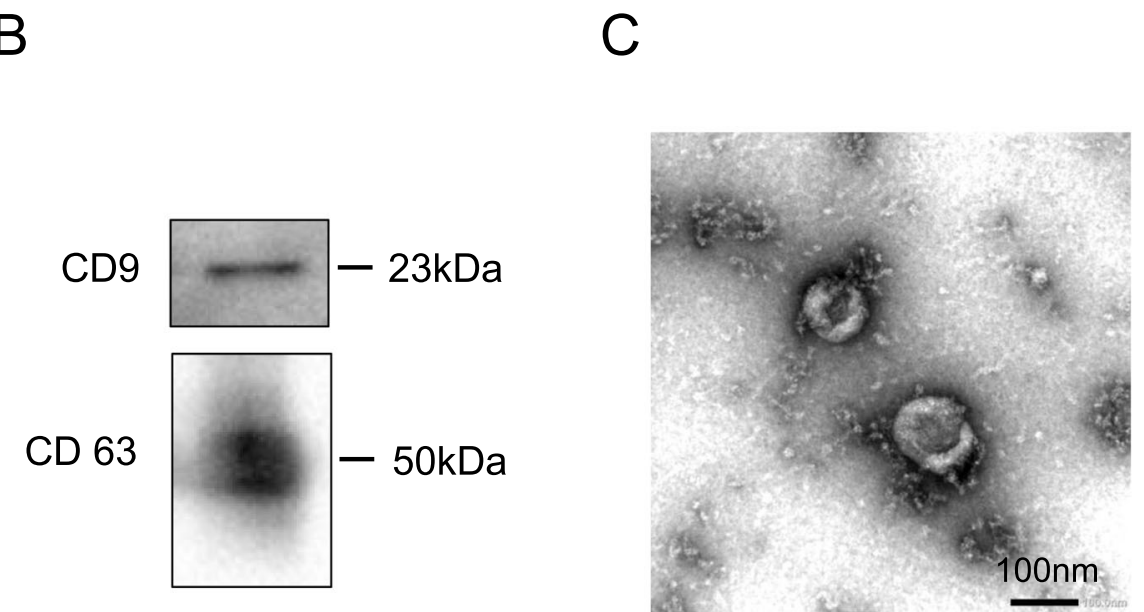

Fig. 1 Characterization of MSC-EVs. A Size distribution of EVs measured in triplicate by NTA. The red area indicates the SD. The 3D plot indicates the EV size, particle number, and intensity measured by NTA. X-axis: number of particles. Y-axis: intensity. Z-axis: number of particles. B Western blotting of EV-associated markers including CD9 and CD63. C MSC-EV morphology was observed by TEM at $\times 50,000$ 
FBS medium with antibiotics for $24 \mathrm{~h}$ to inhibit phosphorylation, and then treated with $2 \times 10^{9}$ particles $/ \mathrm{mL}$ MSC-EVs or PBS for $\leq 20 \mathrm{~min}$. The total cell lysate was prepared with cell lysis buffer (\#9803S; Cell Signaling Technology, Danvers, MA, USA). Antibodies against phospho-p44/42 (\#4370), p44/42 (\#9102), phospho-Akt (\#9271), and Akt (\#9272) were purchased from Cell Signaling Technology.

\section{Inhibition of CXCR 2, AKT, and ERK pathways}

A human chemokine CXCR2 receptor antagonist (SB265610 [\#1559]; Axon Medchem, Groningen, The Netherlands), PI3K signaling inhibitor (LY290042 [\#129-04861]; Wako Pure Chemical Industries Ltd.), and Erk1/Erk2 signaling inhibitor (PD98059 [\#9900]; Cell Signaling Technology) were used to determine the involvement of the CXCR2, AKT, and ERK pathways on the chondrocytes treated with MSC-EVs. Chondrocytes were pre-treated with $20 \mu \mathrm{M}$ SB265610, $7 \mu \mathrm{M}$ LY290042, $20 \mu \mathrm{M}$ PD98059, or dimethyl sulfoxide (DMSO) vehicle for $1 \mathrm{~h}$ and subjected to qRT-PCR, western blotting, and cell growth and migration assays, as previously described.

\section{Statistical analysis}

Data were analyzed using GraphPad Prism v. 8 (GraphPad Software, Inc., La Jolla, CA, USA). A Mann-Whitney $U$ test was used to compare pairs of treatment means. Statistical significance was set to $P<0.05$. Data are presented as means \pm standard deviation (SD).

\section{Results}

Characterization of human synovial MSCs and MSC-EVs

Flow cytometric analysis confirmed that synovial MSCs were positive for CD44, CD73, CD90, and CD105 and negative for CD31 and CD45. The synovial MSCs differentiated into chondrocytes, adipocytes, and calcified (Supplementary Figure 1). Nanoparticle tracking analysis (NTA) showed that the average MSC-EV diameter was $\sim 156.7 \pm 2.8 \mathrm{~nm}$. The diameter of most MSC-EVs was $124.3 \pm 0.4 \mathrm{~nm}$ (Fig. 1A). This finding corroborated that

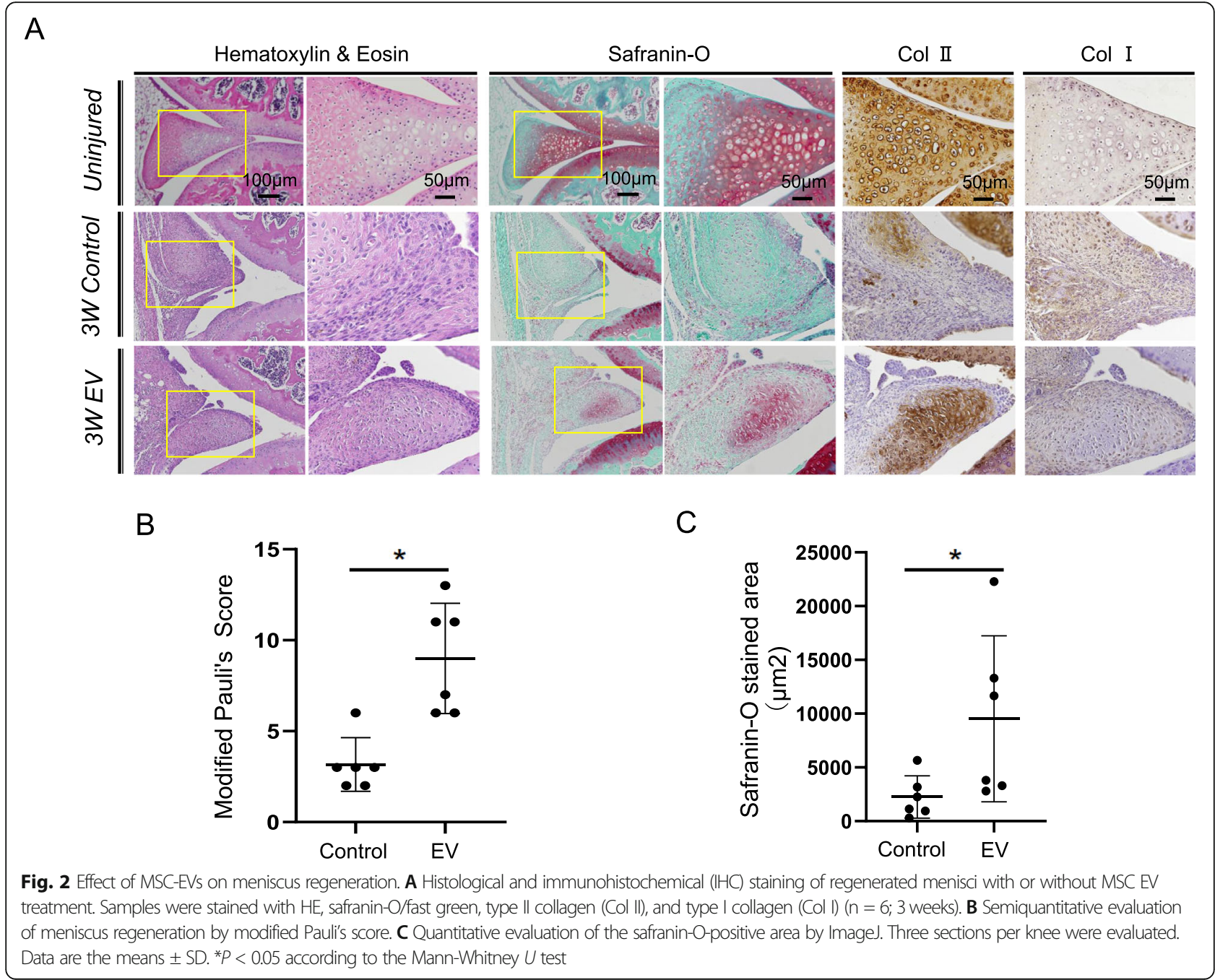


of a previous report [34]. Western blotting confirmed that the MSC-EVs expressed the CD9 and CD63 markers (Fig. 1B). TEM showed that the MSC-EVs were nearly spherical and $\sim 100 \mathrm{~nm}$ in diameter (Fig. 1C).

\section{Effect of MSC-EVs on meniscus regeneration in a mouse meniscus defect model}

In a previous study, mouse meniscus did not spontaneously regenerate 3 weeks after meniscectomy [30]. The surface of the regenerated meniscus was smoother in the EV group compared with that in the control group (Fig. 2A). Safranin$\mathrm{O}$ and type II collagen-positive tissues were observed in the EV group but not in the control group; fibrous type I collagen-positive tissue was observed in the control group. Semiquantitative evaluation by modified Pauli's score indicated that meniscus regeneration was significantly greater in the EV group than that in the control group (Fig. 2B). Quantitative evaluation by ImageJ showed that the safranin-Opositive area was significantly larger in the EV group compared with that in the control group (Fig. 2C).
Effects of MSC-EVs on chondrocyte and synovial MSC cell growth, migration, and chondrogenesis

The main contributors to meniscal regeneration are synovial MSCs and chondrocytes [35]. To investigate the mechanisms through which MSC-EVs accelerate meniscus regeneration, cell growth, migration, and chondrogenesis assays were performed on treated and untreated chondrocytes and synovial MSCs. There were significantly more chondrocytes in the EV group compared with those in the control group (Fig. 3A). The results of the CCK- 8 assay indicated that MSC-EV treatment increased absorbance in a time-dependent manner, and that absorbance was proportional to cell number (Fig. 3B). MSC-EVs significantly increased the relative chondrocyte cell growth from day 3 onwards. The absorbance recorded for the EV group was 4 fourfold higher than that of the control group on day 13. Over time, there were more synovial MSCs in the EV group than in the control group (Fig. 3C). The results of the CCK-8 assay indicated that MSC-EVs significantly increased the relative cell growth of synovial MSC from day 3 (Fig. 3D).
A

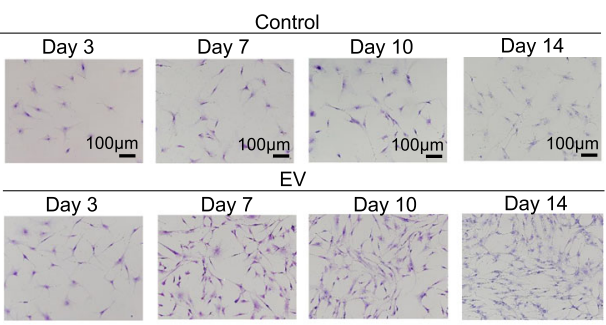

C
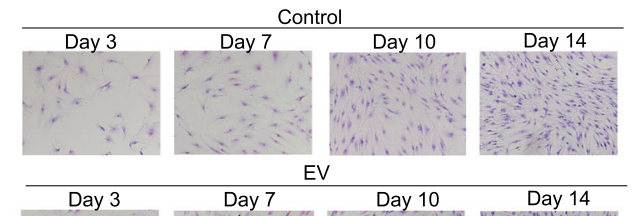

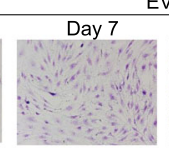

$\mathrm{E}$
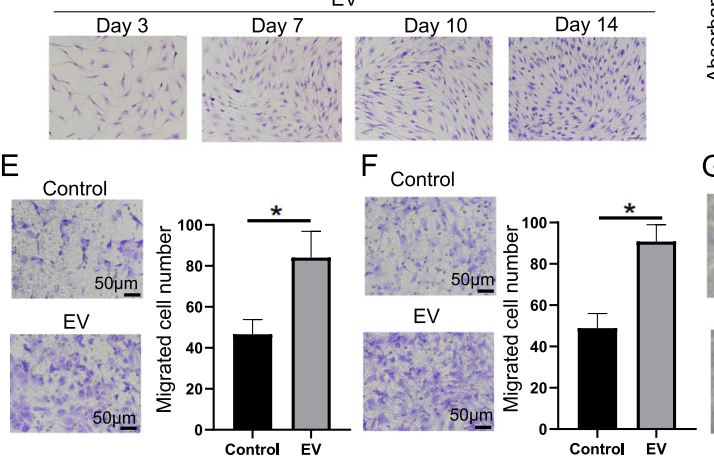

B

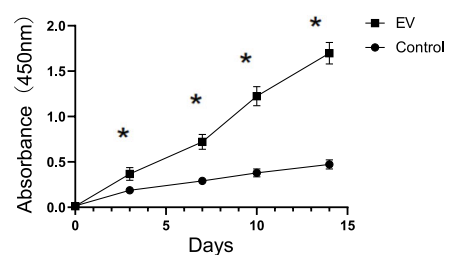

D
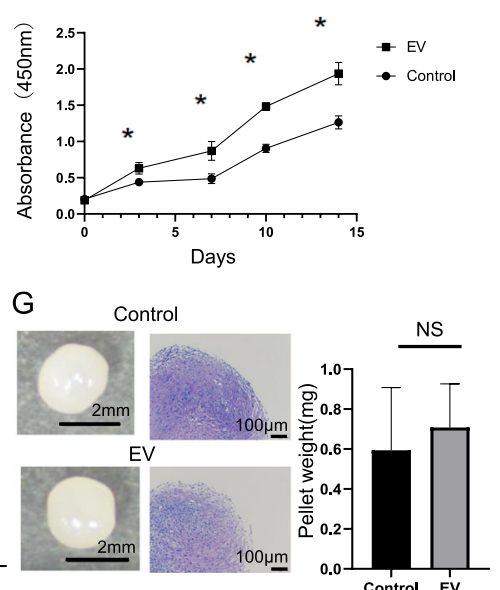

Fig. 3 Effects of MSC-EVs on cell growth, migration, and chondrogenesis. A Chondrocytes cultured with or without MSC-EVs and stained with crystal violet. B CCK-8 cell growth assay in untreated and MSC-EV-treated chondrocytes. Absorbance is proportional to cell number. Measurements were repeated five times, and the average was recorded $(n=6)$. C Synovial MSCs cultured with and without MSC-EVs. D CCK-8 assay on synovial MSCs with and without MSC-EV treatment $(n=6)$. E Transwell assay showing the migration of chondrocytes with and without MSC-EV treatment. Chondrocytes migrating to the lower surface were counted in five randomly selected fields $(n=6)$. F Quantitation of migration by synovial MSCs with and without MSC-EV treatment $(n=6)$. G Macroscopic findings and histological Toluidine Blue staining of chondrogenic pellets of synovial MSCs with and without MSC-EV treatment. Pellets were weighed ( $n=5$; NS, no significant difference; $P=0.84$ ). Data are the means \pm SD. ${ }^{*} P<0.05$ according to the Mann-Whitney $U$ test 
The absorbance recorded for the EV group was $\sim 1.5$ fold higher than that of the control on day 13. The results of the Transwell assay indicated that significantly more chondrocytes and synovial MSCs migrated to the lower surface in the EV group compared with those in the control group (Fig. 3E, F). A pellet culture assay was performed to assess the effects of MSC-EVs on synovial MSC chondrogenesis. The results revealed no significant difference between the EV group and the control groups in terms of pellet appearance, size, or weight (Fig. 3G). Histological analysis based on Toluidine Blue staining revealed no obvious difference between treatments in terms of chondrogenic differentiation on the metachromasia, representing acidic mucopolysaccharide deposition.

\section{Early effect of MSC-EVs on endogenous cell growth and migration in a mouse meniscal defect model}

The results of the in vitro experiments showed that MSC-EVs enhanced the cell growth and migration of chondrocytes and synovial MSCs. Therefore, we investigated the effects of MSC-EVs on the cell growth and migration of endogenous cells at an early time point in the mouse meniscal defect model. Safranin-O and HE staining revealed no obvious differences between the EV and control groups at week 1 (Fig. 4A). This finding was corroborated by semiquantitative modified Pauli's score evaluation (Fig. 4B). PCNA staining revealed a higher number of positive proliferative cells in the EV group compared with that in the control group (Fig. 4A). The number of PCNA-positive cells was significantly higher in the EV group than in the control group (Fig. 4C).

\section{Effects of MSC-EVs on endogenous chondrocyte and synovial MSC gene expression}

RNA sequencing was used to analyze the early gene expression profile of endogenous chondrocytes stimulated by MSC-EVs. The MSC-EVs modulated 168 DEGs (|fold change $>2$ and adjusted $P<0.05)$ in the chondrocytes; of these, 112 were upregulated and 56 were downregulated (Fig. 5A). To identify robustly expressed genes induced by EVs, the gene expression profiles were compared between treated and untreated synovial MSCs. MSC-EV stimulation induced 43 DEGs in synovial MSCs (Supplementary Figure 1). Nine DEGs were upregulated in both the chondrocytes and synovial MSCs treated with EVs (Fig. 5B).

KEGG pathway enrichment analysis identified the gene sets "cytokine-cytokine receptor interaction" and "neuroactive ligand-receptor interaction" as significantly enriched pathways in the EV-treated chondrocytes (Fig. 5C). KEGG pathway enrichment analysis also identified five gene sets in the EV-treated MSCs (Supplementary Figure 2). A proteinprotein interaction database based on the mapping

A

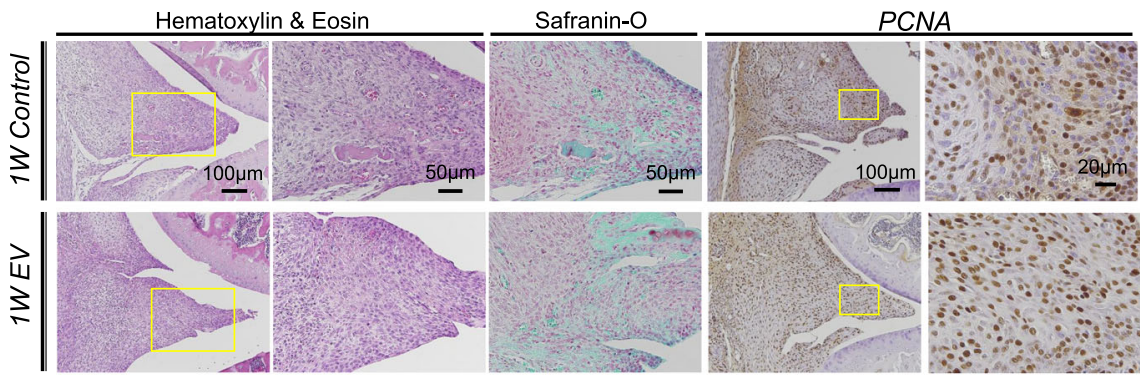

B

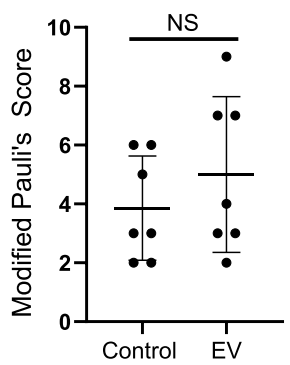

C

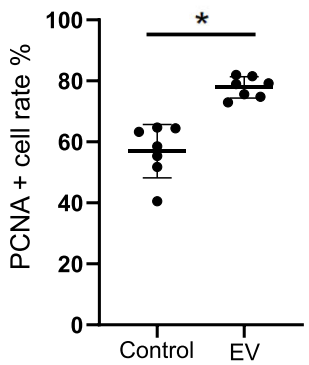

Fig. 4 Early effect of MSC-EVs in a mouse meniscal defect model. A Histology and IHC staining after 1 week in regenerated meniscus with and without MSC-EV treatment $(n=7)$. Samples were stained with $H E$, safranin-O/fast green, and proliferative cell nuclear antigen (PCNA) staining. B Semiquantitative evaluation by modified Pauli's score (NS, no significant difference; $P=0.35$ ). Three sections per knee were evaluated, and the average value was calculated. C Quantitative evaluation of MSC-EV-induced cell growth. The percentage of PCNA-positive cells in regenerated meniscus was estimated using three sections per knee, and the average was calculated $(n=7)$. Data are the mean \pm SD. ${ }^{*} P<0.05$ according to the Mann-Whitney $U$ test 
A

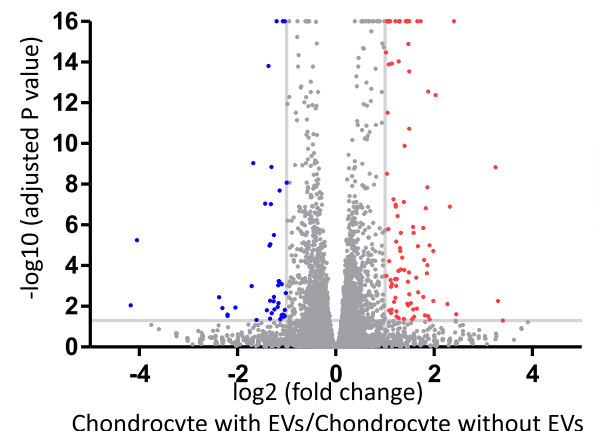

C

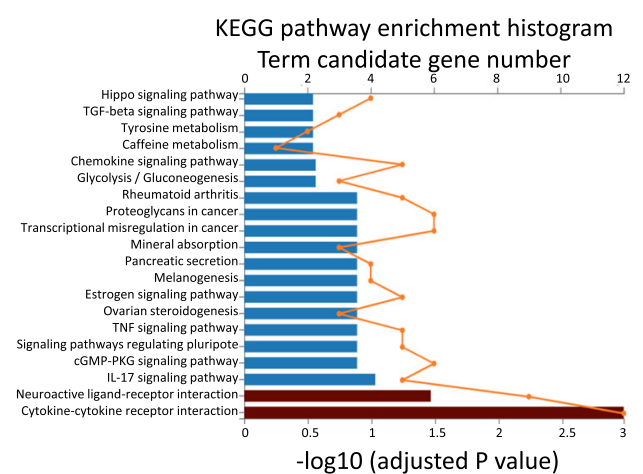

B

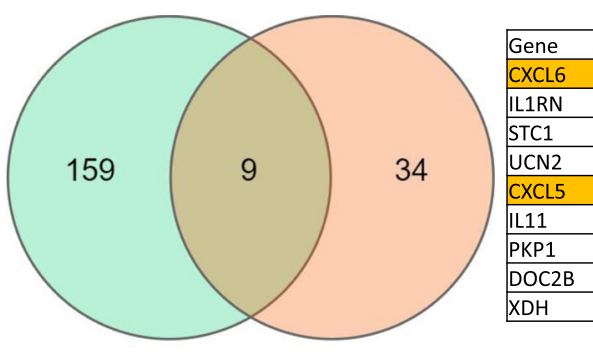

Chondrocyte with EVs /Chondrocyte without EVs MSCs with EVs / MSCs without EVs

D

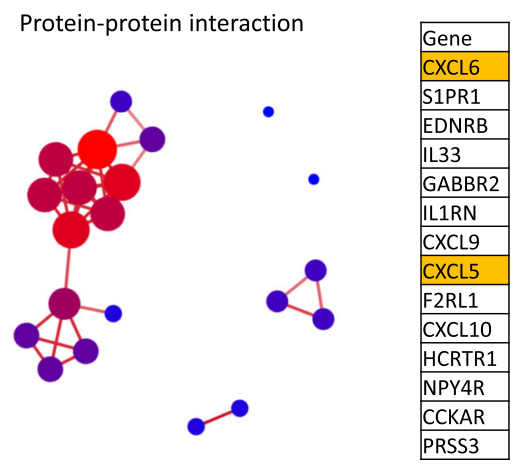

Fig. 5 Effects of MSC-EVs on gene expression in chondrocytes and synovial MSCs. A Volcano plot showing transcriptome/RNA sequencing data for chondrocytes cultured with and without MSC-EVs for $24 \mathrm{~h}(\mathrm{n}=4)$. Red dots represent upregulated DEGs, and blue dots represent downregulated DEGs. B Venn diagram of DEGs in chondrocytes and synovial MSCs. Genes common to both are listed in the table. C Kyoto Encyclopedia of Genes and Genomes (KEGG) pathway analysis. Bars represent Q, and lines represent candidate gene numbers. D Protein-protein interaction on "cytokine-cytokine receptor interaction" and "neuroactive ligand-receptor interaction" gene sets. Symbols for genes composing major clusters are shown in the table

relationship between the STRING11 database output and the NCBI reference transcripts was used to screen for key functional genes in the upregulated gene sets. Fourteen and eight closely related genes were selected through KEGG enrichment and protein-protein interaction analyses in the chondrocytes and synovial MSCs, respectively (Fig. 5D and Supplementary Figure 3). Both methods identified CXCL5 and CXCL6.

\section{Mechanism of MSC-EV-induced chondrocyte cell growth and migration}

We verified the RNA sequencing results by performing qRT-PCR to analyze CXCL5 and CXCL6 expression in MSC-EV-treated chondrocytes. The expression of CXCL5 and CXCL6 was significantly upregulated in the MSC-EV-treated chondrocytes compared to that in the untreated chondrocytes (Fig. 6A). PI3K/Akt or Erk signaling induces CXCL5 and CXCL6 in multiple cell types [36], and EVs regulate the PI3K/Akt and Erk signaling pathways
[37]. To elucidate the signaling pathways through which EVs regulate CXCL5 and CXCL6 expression in chondrocytes, we inhibited MSC-EV-induced AKT and ERK phosphorylation using LY290042 (a PI3K signaling inhibitor) and PD98059 (an Erk1/ Erk2 signaling inhibitor) (Fig. 6B). CXCL5 and CXCL6 upregulation by MSC-EVs $24 \mathrm{~h}$ posttreatment was suppressed by ERK inhibition, but not by AKT inhibition (Fig. 6A). CXCL5 and CXCL6 suppression following ERK inhibition negated the influence of MSC-EVs on chondrocyte cell growth (Fig. 6C, E). The results of the Transwell migration assay revealed that more chondrocytes treated with MSC-EVs migrated to the lower part compared to those in which CXCL5 and CXCL6 were suppressed by ERK inhibition (Fig. 6F). CXCL5 and CXCL6 activate the chemokine CXCR2 receptor [38]. Chemokine CXCR2 receptor antagonist (SB265610) treatment negated the influence of MSC-EVs on chondrocyte cell growth (Fig. 

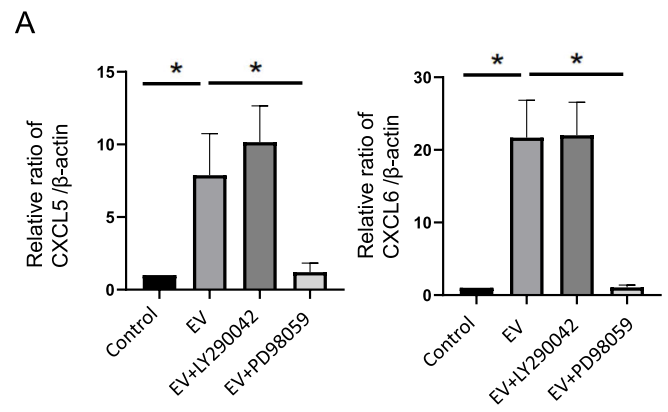

C

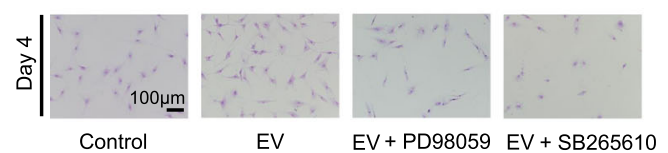

$E$

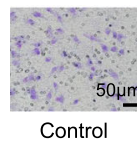

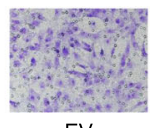

EV

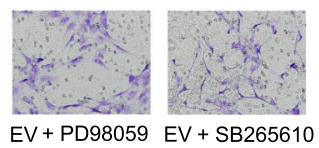

B

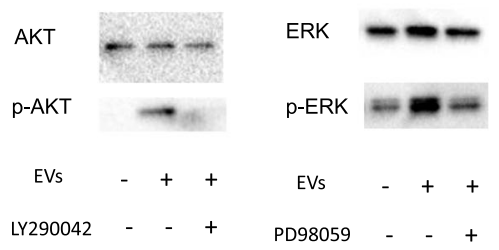

D
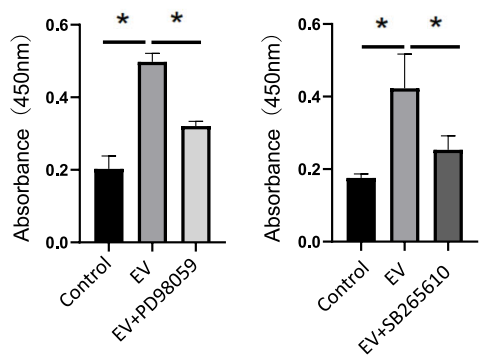

$\mathrm{F}$

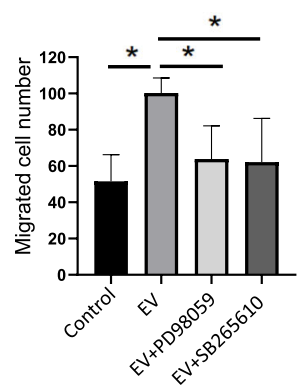

Fig. 6 Mechanistic analysis of chondrocyte cell growth and migration induced by MSC-EVs. A RT-qPCR analysis of CXCL5 and CXCL6 expression in chondrocytes treated with MSC-EVs $(n=6)$. The data shown represent the fold change relative to the control group. AKT and ERK were inhibited using $7 \mu$ M LY290042 and 20 MM PD98059, respectively. B Western blotting following AKT and ERK inhibition in response to MSC-EV treatment. C Chondrocytes were treated with MSC-EVs and an ERK inhibitor or a CXCR2 antagonist and then stained with crystal violet. D CCK-8 cell growth assay of chondrocytes treated with MSC-EVs and an ERK inhibitor or a CXCR2 antagonist. Absorbance corresponds to cell number. Measurements were repeated five times, and the average value was calculated $(n=6)$. E Transwell migration assay of chondrocytes treated with MSC-EVs and an ERK inhibitor or a CXCR2 antagonist. $\mathbf{F}$ Chondrocytes migrating to the lower surface were counted in five randomly selected fields $(n=6)$.

Data are the mean \pm SD. ${ }^{*} P<0.05$ according to the Mann-Whitney $U$ test

6D, E). SB265610 abrogated the increase in chondrocyte migration mediated by MSC-EVs (Fig. 6F).

\section{Discussion}

Intra-articular MSC-EV administration has previously been shown to repair cartilage defects [19]. However, studies on the use of MSC-EVs for the treatment of osteoarthritis have focused on cartilage regeneration. To date, no studies have explored MSC-EV therapy for meniscus defects. To the best of our knowledge, the present study is the first to demonstrate the application of MSCEVs for the management of meniscus damage. Here, we provide empirical evidence for meniscus regeneration by MSC-EVs in a mouse meniscus defect model. There has been a possibility of EVs as a clinical tissue regeneration drug. However, the mechanism through which EVs induce tissue regeneration has not been fully elucidated [39]; this is important to determine in order to optimize the clinical use of MSC-EVs. Two independent bioinformatic analyses were performed based on comprehensive transcriptome/RNA sequencing data, which revealed that MSC-EVs upregulated CXCL5 and CXCL6 in chondrocytes and mediated chondrocyte cell growth and migration via the CXCR2 axis.

The low cellularity of endogenous recruited MSCs and chondrocytes impedes meniscus healing and regeneration [40]. While endogenous MSCs and chondrocytes were found to be successfully recruited for meniscus regeneration in animal models, no disease-modifying treatment is available to regenerate human menisci [41]. EV transplantation may orchestrate cellular processes, such as migration, cell growth, and matrix synthesis, which 
are associated with tissue regeneration [39, 42]. Previous studies have shown that EVs can increase the cell growth and migration of chondrocytes and regenerate cartilage in the proteomic avascular joint resembling the meniscus [21, 43]. In the current study, EVs promoted the migration and cell growth of synovial MSCs and chondrocytes and meniscus regeneration.

CXCL5 and CXCL6 are neutrophil/granulocyte chemotactic factors and are angiogenic during inflammation. CXCL5 and CXCL6 also induce multipotent progenitor cell growth and migration during tissue homeostasis and healing [44-46], and promote migration, inhibit differentiation, and enhance clonogenicity and self-renewal in MSC [46-48]. In adipocytes and endothelial cells, EVs upregulate CXCL5 and CXCL6 via microRNAs or tetraspanins, which are components of the EVs $[49,50]$. Here, RNA sequencing and qRT-PCR analysis confirmed that CXCL5 and CXCL6 were upregulated in chondrocytes and synovial MSCs subjected to MSC-EVs. CXCL5 is induced in fibroblasts and macrophages in response to IL-17 administration. The latter activates the PI3K/Akt and Erk signaling pathways [36]. MicroRNAs and EVs regulate the PI3K/Akt and Erk signaling pathways $[37,51]$. In the present study, MSC-EVs induced CXCL5 and CXCL6 in chondrocytes through activation of the Erk signaling pathway.

CXCR2 is a major ELR-CXC chemokine receptor [38], which shares $78 \%$ sequence homology with CXCR1; both bind to CXCL6. However, CXCR1 binds to CXCL6 and CXCL8, but not to CXCL5 [52]. CXCR2 interacts with higher-affinity ELR+ chemokines and plays a vital role in cellular chemotaxis [53]. CXCR2 signaling supports cellular migration, survival, and growth [54, 55]. In tissue progenitor cells, CXCR2 signaling contributes to tissue healing, providing insights into cell-based tissue damage therapy [54, 56, 57]. An earlier study showed that CXCR2 signaling in chondrocytes inhibited apoptosis and maintained the chondrocyte phenotype and cartilage homeostasis [44]. Here, we revealed that EVs activated CXCR2 signaling and promoted chondrocyte cell growth and migration.

\section{Conclusions}

The results of this study demonstrate that intra-articular MSC-EV administration repaired meniscus defects and enhanced chondrocyte and synovial MSC cell growth and migration. Comprehensive transcriptome/RNA sequencing data demonstrated that MSC-EVs robustly upregulated CXCL5 and CXCL6 in chondrocytes and mediated the cell growth and migration of these cells via the CXCR2 axis.

\section{Abbreviations}

MSCs: Mesenchymal stromal cells; EVs: Extracellular vesicles; CXCR2: C-X-C chemokine receptor 2; CXCL: C-X-C motif chemokine ligand;
OA: Osteoarthritis; MEM: Minimal essential medium; FBS: Fetal bovine serum; DMEM: Dulbecco's modified Eagle's medium; PBS: Phosphate-buffered saline; NTA: Nanoparticle tracking analysis; TEM: Transmission electron microscope; CCK-8: Cell Counting Kit-8; PFA: Paraformaldehyde; BMP-7: Bone morphogenetic protein-7; TGF- $\beta 3$ : Transforming growth factor- $\beta 3$; EDTA:: Ethylenediaminetetraacetic acid; HE: Hematoxylin and eosin; PCNA: Proliferative cell nuclear antigen; BSA: Bovine serum albumin; DAB: Diaminobenzidine; DEGs: Differentially expressed genes; KEGG: Kyoto Encyclopedia of Genes and Genomes; qRT-PCR: Real-time quantitative polymerase chain reaction; cDNA: Complementary DNA; p-AKT: PhosphoAKT; p-ERK: Phospho-extracellular regulated protein kinases;

PI3K: Phosphatidylinositol-4,5-bisphosphate 3-kinase; SD: Standard deviation

\section{Supplementary Information}

The online version contains supplementary material available at https://doi. org/10.1186/s13287-021-02481-9.

Additional file 1: Fig. S1. Expression of positive and negative cellsurface markers in mesenchymal stromal cells (MSCs), and their differentiation potential. (A) Representative flow cytometric profiles of colonyforming synovium-derived MSCs stained for CD44, CD73, CD90, and CD105 (positive cell-surface markers), and CD45 and CD31(negative cellsurface markers) (purple: isotype control; red: sample). (B) Chondrogenesis. Histological sections stained with toluidine bule are shown. (C) Adipogenesis. Culture dishes stained with oil red-O are shown. (D) Calcification. Culture dishes stained with alizarin red are shown. Fig. S2. Effect of MSC EVs on meniscus regeneration. Histological and immunohistochemical $(\mathrm{IHC})$ staining of the best and the worst regenerated menisci with or without MSCs EV treatment. Samples were stained with HE, safranin-O/ fast green, type II collagen (Col II), and type I collagen (Col I) $(n=6 ; 3$ weeks). Fig. S3. Early effect of MSC-EVs in a mouse meniscal defect model. IHC evaluation of proliferative cell nuclear antigen (PCNA) staining after 1 week in the best and the worst regenerated meniscus with and without MSC-EV treatment. Fig. S4. Volcano plot presenting the transcriptome/RNA sequencing data for synovial MSCs cultured with or without MSC-EVs for $24 \mathrm{~h}(\mathrm{n}=4)$. Gene set enrichment analysis. Fig. S5. KEGG pathway analysis of synovial MSCs treated with MSC-EVs. Fig. S6. Protein-protein interactions on upregulated gene set in synovial MSCs treated with MSC-EVs.

Additional file 2: Table S1. Antibodies used for cytometric analyses. Additional file 3: Table S2. Criteria and scores used for the histological assessment of regenerated menisci (Modified Pauli's Score, A:3, B:2, C:1, D:0).

Additional file 4: Table S3. RNA sequencing data for chondrocytes and synovial MSCs cultured with or without MSC-EVs.

Additional file 5: Table S4. Sequences of primers used for RT-qPCR analysis.

\section{Acknowledgements}

The authors thank Atsushi Okawa, MD, PhD, for the continuous support, Miyoko Ojima for the management of our department, and Editage (www. editage.jp) for the English language editing. This research did not receive any specific grant from funding agencies in the public, commercial, or notfor-profit sectors.

\section{Authors' contributions}

KK conceived the study, performed all the experiments, and participated in its design. HK and KT participated in the study design and performed the analyses. YN and KM acquired the data. IS analyzed the data. TY participated in the study design. HK had full access to the study data and takes responsibility for the integrity of the data and the accuracy of the data analysis.

All authors have read and approved the final manuscript and take responsibility for the integrity of the data and the accuracy of the data analysis.

Funding

Not applicable. 


\section{Availability of data and materials}

The datasets used and analyzed during the current study are available from the corresponding authors upon reasonable request.

\section{Declarations}

\section{Ethics approval and consent to participate}

This study was approved by the Medical Research Ethics Committee of Tokyo Medical and Dental University, and informed consent was obtained from all study subjects. All animal experiments were conducted in accordance with the guidelines of the Institutional Animal Care and Use Committee of Tokyo Medical and Dental University.

\section{Consent for publication}

Not applicable.

\section{Competing interests}

The authors declare that they have no competing interests.

\section{Author details}

${ }^{1}$ Department of Joint Surgery and Sports Medicine, Graduate School of Medical and Dental Sciences, Tokyo Medical and Dental University (TMDU), 1-5-45 Yushima, Bunkyo-ku, Tokyo 113-8519, Japan. ${ }^{2}$ Department of Neurology and Neurological Science, Graduate School of Medical and Dental Sciences and Center for Brain Integration Research, Tokyo Medical and Dental University (TMDU), 1-5-45 Yushima, Bunkyo-Ku, Tokyo 113-8519, Japan. ${ }^{3}$ Center for Stem Cell and Regenerative Medicine, Tokyo Medical and Dental University (TMDU), 1-5-45 Yushima, Bunkyo-ku, Tokyo 113-8519, Japan. ${ }^{4}$ Department of Orthopedics, Dokkyo Medical University Saitama Medical Center, 2-1-50 Minamikoshigaya, Koshigaya, Saitama 343-8555, Japan.

Received: 10 March 2021 Accepted: 29 June 2021

Published online: 22 July 2021

\section{References}

1. Bedi A, Kelly NH, Baad M, Fox AJ, Brophy RH, Warren RF, et al. Dynamic contact mechanics of the medial meniscus as a function of radial tear, repair, and partial meniscectomy. J Bone Joint Surg Am. 2010;92(6):1398408. https://doi.org/10.2106/JBJS.I.00539.

2. Driban JB, Davis JE, Lu B, Price LL, Ward RJ, MacKay JW, et al. Accelerated knee osteoarthritis is characterized by destabilizing meniscal tears and preradiographic structural disease burden. Arthritis Rheum. 2019;71(7):1089-100.

3. Beaufils P, Pujol N. Management of traumatic meniscal tear and degenerative meniscal lesions. Save the meniscus. Orthop Traumatol Surg Res. 2017;103(8 s):S237-s44.

4. Antony B, Driban JB, Price LL, Lo GH, Ward RJ, Nevitt M, et al. The relationship between meniscal pathology and osteoarthritis depends on the type of meniscal damage visible on magnetic resonance images: data from the Osteoarthritis Initiative. Osteoarthr Cartil. 2017;25(1):76-84. https://doi. org/10.1016/j.joca.2016.08.004.

5. Koh JL, Yi SJ, Ren Y, Zimmerman TA, Zhang LQ. Tibiofemoral contact mechanics with horizontal cleavage tear and resection of the medial meniscus in the human knee. J Bone Joint Surg Am. 2016;98(21):1829-36. https://doi.org/10.2106/JBJS.16.00214.

6. Seedhom BB, Hargreaves DJ. Transmission of the load in the knee joint with special reference to the role of the menisci: part II: experimental results, discussion and conclusions. Eng Med. 1979;8(4):220-8. https://doi.org/1 0.1243/EMED_JOUR_1979_008_051_02.

7. Persson F, Turkiewicz A, Bergkvist D, Neuman P, Englund M. The risk of symptomatic knee osteoarthritis after arthroscopic meniscus repair vs partial meniscectomy vs the general population. Osteoarthr Cartil. 2018;26(2):195201. https://doi.org/10.1016/j.joca.2017.08.020.

8. Englund M, Roos EM, Lohmander LS. Impact of type of meniscal tear on radiographic and symptomatic knee osteoarthritis: a sixteen-year followup of meniscectomy with matched controls. Arthritis Rheum. 2003;48(8):217887. https://doi.org/10.1002/art.11088.

9. Pujol N, Beaufils P. Save the meniscus again! Knee Surg Sports Traumatol Arthrosc. 2019;27(2):341-2. https://doi.org/10.1007/s00167-018-5325-4.

10. Doral MN, Bilge O, Huri G, Turhan E, Verdonk R. Modern treatment of meniscal tears. EFORT Open Rev. 2018;3(5):260-8. https://doi.org/10.1302/2 058-5241.3.170067.
11. Katagiri H, Muneta T, Tsuji K, Horie M, Koga H, Ozeki N, et al. Transplantation of aggregates of synovial mesenchymal stem cells regenerates meniscus more effectively in a rat massive meniscal defect. Biochem Biophys Res Commun. 2013;435(4):603-9. https://doi.org/10.1016/j.bbrc.2013.05.026.

12. Chew E, Prakash R, Khan W. Mesenchymal stem cells in human meniscal regeneration: a systematic review. Ann Med Surg. 2017;24:3-7.

13. Spees JL, Lee RH, Gregory CA. Mechanisms of mesenchymal stem/stromal cell function. Stem Cell Res Ther. 2016;7(1):125. https://doi.org/10.1186/s132 87-016-0363-7.

14. Makarova J, Turchinovich A, Shkurnikov M, Tonevitsky A. Extracellular miRNAs and cell-cell communication: problems and prospects. Trends Biochem Sci. 2021. https://doi.org/10.1016/j.tibs.2021.01.007.

15. Shi J, Zhao YC, Niu ZF, Fan HJ, Hou SK, Guo XQ, et al. Mesenchymal stem cell-derived small extracellular vesicles in the treatment of human diseases: progress and prospect. World J Stem Cells. 2021;13(1):49-63. https://doi. org/10.4252/wjsc.v13.11.49.

16. Kesidou D, da Costa Martins PA, de Windt LJ, Brittan M, Beqqali A, Baker AH. Extracellular vesicle miRNAs in the promotion of cardiac neovascularisation. Front Physiol. 2020;11:579892. https://doi.org/10.3389/fphys.2020.579892.

17. Lv LL, Wu WJ, Feng Y, Li ZL, Tang TT, Liu BC. Therapeutic application of extracellular vesicles in kidney disease: promises and challenges. J Cell Mol Med. 2018;22(2):728-37. https://doi.org/10.1111/jcmm.13407.

18. Casado-Diaz A, Quesada-Gomez JM, Dorado G. Extracellular vesicles derived from mesenchymal stem cells (MSC) in regenerative medicine: applications in skin wound healing. Front Bioeng Biotechnol. 2020;8:146. https://doi. org/10.3389/fbioe.2020.00146.

19. De Luna A, Otahal A, Nehrer S. Mesenchymal stromal cell-derived extracellular vesicles - silver linings for cartilage regeneration? Front Cell Dev Biol. 2020;8:593386. https://doi.org/10.3389/fcell.2020.593386.

20. Woo CH, Kim HK, Jung GY, Jung YJ, Lee KS, Yun YE, et al. Small extracellular vesicles from human adipose-derived stem cells attenuate cartilage degeneration. J Extracell Vesicles. 2020;9(1):1735249. https://doi.org/10.1 080/20013078.2020.1735249.

21. Li S, StockI S, Lukas C, Gotz J, Herrmann M, Federlin M, et al. hBMSC-derived extracellular vesicles attenuate IL-1 beta-induced catabolic effects on OAchondrocytes by regulating pro-inflammatory signaling pathways. Front Bioeng Biotechnol. 2020;8:603598. https://doi.org/10.3389/fbioe.2020.603598.

22. Zhang S, Teo KYW, Chuah SJ, Lai RC, Lim SK, Toh WS. MSC exosomes alleviate temporomandibular joint osteoarthritis by attenuating inflammation and restoring matrix homeostasis. Biomaterials. 2019;200:3547. https://doi.org/10.1016/j.biomaterials.2019.02.006.

23. Keshtkar S, Azarpira N, Ghahremani MH. Mesenchymal stem cell-derived extracellular vesicles: novel frontiers in regenerative medicine. Stem Cell Res Ther. 2018;9(1):63. https://doi.org/10.1186/s13287-018-0791-7.

24. Ghadially FN, Lalonde JM, Wedge JH. Ultrastructure of normal and torn menisci of the human knee joint. J Anat. 1983;136(Pt 4):773-91.

25. Ozeki N, Muneta T, Matsuta S, Koga H, Nakagawa Y, Mizuno M, et al. Synovia mesenchymal stem cells promote meniscus regeneration augmented by an autologous Achilles tendon graft in a rat partial meniscus defect model. Stem Cells. 2015;33(6):1927-38. https://doi.org/10.1002/stem.2030.

26. Amemiya M, Tsuji K, Katagiri H, Miyatake K, Nakagawa Y, Sekiya I, et al. Synovial fluid-derived mesenchymal cells have non-inferior chondrogenic potential and can be utilized for regenerative therapy as substitute for synovium-derived cells. Biochem Biophys Res Commun. 2020;523(2):465-72. https://doi.org/10.1016/j.bbrc.2019.12.068.

27. Katagiri H, Mendes LF, Luyten FP. Definition of a critical size osteochondral knee defect and its negative effect on the surrounding articular cartilage in the rat. Osteoarthr Cartil. 2017;25(9):1531-40. https://doi.org/10.1016/j.joca.2 017.05.006

28. Ogata Y, Mabuchi Y, Shinoda K, Horiike Y, Mizuno M, Otabe K, et al. Anterior cruciate ligament-derived mesenchymal stromal cells have a propensity to differentiate into the ligament lineage. Regen Ther. 2018;8:20-8. https://doi. org/10.1016/j.reth.2017.12.001.

29. Zhu Y, Wang Y, Zhao B, Niu X, Hu B, Li Q, et al. Comparison of exosomes secreted by induced pluripotent stem cell-derived mesenchymal stem cells and synovial membrane-derived mesenchymal stem cells for the treatment of osteoarthritis. Stem Cell Res Ther. 2017;8(1):64. https://doi.org/10.1186/ s13287-017-0510-9.

30. Hiyama K, Muneta T, Koga H, Sekiya I, Tsuji K. Meniscal regeneration after resection of the anterior half of the medial meniscus in mice. J Orthop Res. 2017;35(9):1958-65. https://doi.org/10.1002/jor.23470. 
31. Love MI, Huber W, Anders S. Moderated estimation of fold change and dispersion for RNA-seq data with DESeq2. Genome Biol. 2014;15(12):550. https://doi.org/10.1186/s13059-014-0550-8.

32. Tsuji K, Bandyopadhyay A, Harfe BD, Cox K, Kakar S, Gerstenfeld L, et al. BMP2 activity, although dispensable for bone formation, is required for the initiation of fracture healing. Nat Genet. 2006;38(12):1424-9. https://doi. org/10.1038/ng1916.

33. Tsuji K, Kraut N, Groudine $M$, Noda M. Vitamin $D_{3}$ enhances the expression of I-mfa, an inhibitor of the MyoD family, in osteoblasts. Biochim Biophys Acta. 2001;1539(1-2):122-30. https://doi.org/10.1016/S0167-4889(01)00099-4.

34. Wu J, Kuang L, Chen C, Yang J, Zeng WN, Li T, et al. miR-100-5p-abundant exosomes derived from infrapatellar fat pad MSCs protect articular cartilage and ameliorate gait abnormalities via inhibition of mTOR in osteoarthritis. Biomaterials. 2019;206:87-100.

35. Kim W, Onodera T, Kondo E, Terkawi MA, Homan K, Hishimura R, et al. Which contributes to meniscal repair, the synovium or the meniscus? An in vivo rabbit model study with the freeze-thaw method. Am J Sports Med. 2020;48(6):1406-15. https://doi.org/10.1177/0363546520906140.

36. Pickens SR, Chamberlain ND, Volin MV, Gonzalez M, Pope RM, Mandelin AM 2nd, et al. Anti-CXCL5 therapy ameliorates IL-17-induced arthritis by decreasing joint vascularization. Angiogenesis. 2011;14(4):443-55. https://doi. org/10.1007/s10456-011-9227-z.

37. Gangadaran $\mathrm{P}$, Rajendran RL, Lee HW, Kalimuthu S, Hong CM, Jeong SY, et al. Extracellular vesicles from mesenchymal stem cells activates VEGF receptors and accelerates recovery of hindlimb ischemia. J Control Release. 2017;264:112-26. https://doi.org/10.1016/j.jconrel.2017.08.022.

38. Addison CL, Daniel TO, Burdick MD, Liu H, Ehlert JE, Xue YY, et al. The CXC chemokine receptor 2, CXCR2, is the putative receptor for ELR+ CXC chemokine-induced angiogenic activity. J Immunol. 2000;165(9):5269-77.

39. Wu X, Wang Y, Xiao Y, Crawford R, Mao X, Prasadam I. Extracellular vesicles: potential role in osteoarthritis regenerative medicine. J Orthop Translat. 2020:21:73-80. https://doi.org/10.1016/j.jot.2019.10.012.

40. Mauck RL, Burdick JA. From repair to regeneration: biomaterials to reprogram the meniscus wound microenvironment. Ann Biomed Eng. 2015; 43(3):529-42. https://doi.org/10.1007/s10439-015-1249-z.

41. Guo W, Xu W, Wang Z, Chen M, Hao C, Zheng X, et al. Cell-free strategies for repair and regeneration of meniscus injuries through the recruitment of endogenous stem/progenitor cells. Stem Cells Int. 2018:2018:5310471.

42. Esmaeili A, Hosseini S, Baghaban EM. Engineered-extracellular vesicles as an optimistic tool for microRNA delivery for osteoarthritis treatment. Cell Mol Life Sci. 2021;78(1):79-91. https://doi.org/10.1007/s00018-020-03585-w.

43. Wang K, Li F, Yuan Y, Shan L, Cui Y, Qu J, et al. Synovial mesenchymal stem cell-derived EV-packaged miR-31 downregulates histone demethylase KDM2A to prevent knee osteoarthritis. Mol Ther Nucleic Acids. 2020;22: 1078-91. https://doi.org/10.1016/j.omtn.2020.09.014.

44. Sherwood J, Bertrand J, Nalesso G, Poulet B, Pitsillides A, Brandolini L, et al. A homeostatic function of CXCR2 signalling in articular cartilage. Ann Rheum Dis. 2015;74(12):2207-15. https://doi.org/10.1136/annrheumdis-2 014-205546.

45. Mishra PJ, Mishra PJ, Banerjee D. Cell-free derivatives from mesenchymal stem cells are effective in wound therapy. World J Stem Cells. 2012;4(5):3543. https://doi.org/10.4252/wjsc.v4.i5.35.

46. Xu S, Chan RWS, Li T, Ng EHY, Yeung WSB. Understanding the regulatory mechanisms of endometrial cells on activities of endometrial mesenchymal stem-like cells during menstruation. Stem Cell Res Ther. 2020;11(1):239. https://doi.org/10.1186/s13287-020-01750-3.

47. Liu W, Wang P, Xie Z, Wang S, Ma M, Li J, et al. Abnormal inhibition of osteoclastogenesis by mesenchymal stem cells through the miR-4284/ CXCL5 axis in ankylosing spondylitis. Cell Death Dis. 2019;10(3):188. https:// doi.org/10.1038/s41419-019-1448-x.

48. Zhao $\mathrm{Y}$, Zhang $\mathrm{H}$. Update on the mechanisms of homing of adipose tissuederived stem cells. Cytotherapy. 2016;18(7):816-27. https://doi.org/10.1016/j. jcyt.2016.04.008

49. De Silva N, Samblas M, Martínez JA, Milagro Fl. Effects of exosomes from LPS-activated macrophages on adipocyte gene expression, differentiation, and insulin-dependent glucose uptake. J Physiol Biochem. 2018;74(4):55968. https://doi.org/10.1007/s13105-018-0622-4.

50. Nazarenko I, Rana S, Baumann A, McAlear J, Hellwig A, Trendelenburg M, et al. Cell surface tetraspanin Tspan 8 contributes to molecular pathways of exosome-induced endothelial cell activation. Cancer Res. 2010:70(4):166878. https://doi.org/10.1158/0008-5472.CAN-09-2470.
51. Blahna MT, Hata A. Regulation of miRNA biogenesis as an integrated component of growth factor signaling. Curr Opin Cell Biol. 2013;25(2):23340. https://doi.org/10.1016/j.ceb.2012.12.005.

52. Nasser MW, Raghuwanshi SK, Grant DJ, Jala VR, Rajarathnam K, Richardson RM. Differential activation and regulation of CXCR1 and CXCR2 by CXCL8 monomer and dimer. J Immunol. 2009;183(5):3425-32.

53. Cheng $Y$, Ma XL, Wei $Y Q$, Wei XW. Potential roles and targeted therapy of the CXCLs/CXCR2 axis in cancer and inflammatory diseases. Biochim Biophys Acta Rev Cancer. 2019;1871(2):289-312. https://doi.org/10.1016/j. bbcan.2019.01.005.

54. Li Z, Yang A, Yin X, Dong S, Luo F, Dou C, et al. Mesenchymal stem cells promote endothelial progenitor cell migration, vascularization, and bone repair in tissue-engineered constructs via activating CXCR2-Src-PKL/Nav2Rac1. FASEB J. 2018;32(4):2197-211.

55. Almeida CR, Caires HR, Vasconcelos DP, Barbosa MA. NAP-2 secreted by human NK cells can stimulate mesenchymal stem/stromal cell recruitment. Stem Cell Rep. 2016;6(4):466-73. https://doi.org/10.1016/j.stemcr.2016.02.012.

56. Shen Z, Wang J, Huang Q, Shi Y, Wei Z, Zhang X, et al. Genetic modification to induce CXCR2 overexpression in mesenchymal stem cells enhances treatment benefits in radiation-induced oral mucositis. Cell Death Dis. 2018; 9(2):229. https://doi.org/10.1038/s41419-018-0310-X.

57. Yang A, Lu Y, Xing J, Li Z, Yin X, Dou C, et al. IL-8 enhances therapeutic effects of BMSCs on bone regeneration via CXCR2-mediated PI3k/Akt signaling pathway. Cell Physiol Biochem. 2018:48(1):361-70.

\section{Publisher's Note}

Springer Nature remains neutral with regard to jurisdictional claims in published maps and institutional affiliations.

Ready to submit your research? Choose BMC and benefit from:

- fast, convenient online submission

- thorough peer review by experienced researchers in your field

- rapid publication on acceptance

- support for research data, including large and complex data types

- gold Open Access which fosters wider collaboration and increased citations

- maximum visibility for your research: over $100 \mathrm{M}$ website views per year

At BMC, research is always in progress.

Learn more biomedcentral.com/submissions 